\title{
Edukasi Eksistensi dan Keberlanjutan Ekosistem Hutan Mangrove untuk Remaja
}

\author{
Nafiah Solikhah \\ Prodi S1 Arsitektur, Jurusan Arsitektur dan Perencanaan, Universitas Tarumanagara, \\ Jakarta, Indonesia \\ Author E-mail: nafiahs@ft.untar.ac.id
}

\section{A B S T R A K}

Indonesia memiliki 3,4 juta hektar atau $24 \%$ dari total 13,8 juta hektar hutan mangrove dunia. Dalam perkembangannya, luas mangrove Indonesia terus mengalami penurunan dan tercatat seluas 637.624 hektar $(18,95 \%)$ dalam kondisi kritis karena penutupan tajuk yang kurang dari $60 \%$. Hutan mangrove bermanfaat untuk meredam gelombang besar termasuk tsunami, mencegah abrasi, menyerap karbondioksida 5 kali lebih besar daripada hutan tropis di dataran tinggi, dan sebagai habitat bagi beberapa jenis satwa liar, dengan demikian, Indonesia memiliki peranan yang sangat signifikan bagi eksistensi dan keberlanjutan hutan mangrove dunia. Berdasarkan data tahun 2018, Propinsi DKI Jakarta memiliki 300 hektar atau sekitar $10,7 \%$ dari total hutan mangrove di Indonesia yang tersebar di Taman Wisata Alam Angke Kapuk, Suaka Margasatwa Muara Angke, Hutan Lindung Angke Kapuk dan Hutan Produksi Kamal Muara sekaligus merupakan bagian dari hutan mangrove terakhir yang tersisa di provinsi DKI Jakarta. Berdasarkan fenomena tersebut, maka diperlukan upaya untuk menjaga eksistensi dan keberlanjutan hutan mangrove khususnya di Kota Jakarta. Salah satu aktor penting dalam upaya tersebut adalah kalangan remaja dengan tumbuhnya kesadaran akan isu lingkungan. Remaja sebagai pemegang tonggak masa depan perlu memahami pentingnya eksistensi dan keberlanjutan hutan mangrove. Permasalahan yang dihadapi adalah perlunya sebuah kegiatan edukasi yang sesuai dengan karakteristik bagi remaja. Oleh karena itu, tim pelaksana menginisiasi edukasi eksistensi dan keberlanjutan ekosistem hutan mangrove bagi remaja (berusia 12 - 24 tahun) di Kampung Tanjung Gedong yang tergabung dalam Remaja Masjid At-Taufiq Tanjung Gedong dengan pendekatan Experiential Learning Discovery Journey yang dilaksanakan dalam 3 (tiga) tahap, yaitu tahap pengenalan dengan memberikan materi infografis dan videografis, tahap observasi dengan kunjungan ke Taman Wisata Alam Mangrove, Angke Kapuk, Jakarta Utara; dan tahap refleksi melalui instrumen refleksi yang diisi oleh mitra. Berdasarkan hasil kegiatan, diketahui seluruh responden telah memiliki pengalaman teoretis tentang eksistensi dan keberlanjutan hutan mangrove yang diperoleh dari bangku sekolah. Kegiatan pengabdian kepada masyarakat (PkM) memberikan pengalaman baru dalam proses kreatif untuk memahami topik PkM yaitu eksistensi dan keberlanjutan ekosistem hutan mangrove di Jakarta.

Kata Kunci: Edukasi Remaja, Hutan Mangrove, Hutan Mangrove Jakarta; Experiential Learning Discovery Journey. 


\begin{abstract}
A B S T R A C T
Indonesia has 3.4 million hectares or $24 \%$ of the world's 13.8 million hectares of mangrove forests. In its development, Indonesia's mangrove area continues to decline, and it is recorded that an area of 637,624 hectares (18.95\%) is in critical condition due to canopy cover which is less than $60 \%$. Mangrove forests can absorb large waves including tsunamis, prevent abrasion, absorb carbon dioxide 5 times greater than tropical forests in the highlands, and are a habitat for several types of wildlife. Thus, Indonesia has a very significant role in the existence and sustainability of the world's mangrove forests. Based on 2018 data, DKI Jakarta Province has 300 hectares or about 10.7\% of the total mangrove forest in Indonesia which is spread in the Angke Kapuk Nature Park, Muara Angke Wildlife Sanctuary, Angke Kapuk Protection Forest and Kamal Muara Production Forest as well as part of the last remaining mangrove forest in DKI Jakarta province. Based on this phenomenon, efforts are needed to maintain the existence and sustainability of mangrove forests, especially in the city of Jakarta. One of the important actors in this effort is the youth with growing awareness of environmental issues. Teenagers as future milestone holders need to understand the importance of the existence and sustainability of mangrove forests. The problem faced is the need for an educational activity that is by the characteristics of adolescents. Therefore, the implementing team initiated education on the existence and sustainability of the mangrove forest ecosystem for youth (12-24 years old) in Tanjung Gedong Village who are members of the At-Taufiq Tanjung Gedong Mosque Youth. Using the Experiential Learning Discovery Journey approach the program was carried out in 3 (three) stages: The introduction stage by providing infographics and videographics materials; The observation stage with a visit to the Mangrove Nature Tourism Park, Angke Kapuk, North Jakarta; The reflection stage through reflection instruments filled out by partners. Based on the results of the activity, it is known that all respondents have theoretical experience about the existence and sustainability of mangrove forests obtained from the school. Community service activities $(\mathrm{PkM})$ provide new experiences in the creative process to understand the topic of PkM, namely the existence and sustainability of mangrove forest ecosystems in Jakarta.
\end{abstract}

Keywords: Youth's Education, Mangrove Forest, Jakarta's Mangrove Forest; Experiential Learning Discovery Journey.

Copyright $(\subseteq 2021$ Authors. This is an open access article distributed under the Creative Commons Attribution License, which permits unrestricted use, distribution, and reproduction in any medium, provided the original work is properly cited.

\section{PENDAHULUAN}

Berdasarkan simulasi yang dilakukan oleh Bunting, dkk (2018) menggunakan sensor data ALOS PALSAR and Landsat, terdeteksi terdapat 13,8 juta hektar hutan mangrove di dunia, dimana $38,7 \%$ diantaranya berada di Asia. Pada rilis pemetaan Mangrove Nasional yang dilakukan oleh Kementerian Lingkungan Hidup dan Kehutanan Tahun 2021, Indonesia memiliki 3,4 juta hektar atau sekitar $24 \%$ dari total 13,8 juta hektar hutan mangrove dunia. Dalam perkembangannya, saat ini luas mangrove Indonesia terus mengalami penurunan dan tercatat seluas 637.624 hektar
(18,95\%) dalam kondisi kritis karena penutupan tajuk yang kurang dari 60\% (Bunting et al., 2018; Adkhi, 2020; Direktorat Pendayagunaan Pesisir dan Pulau-Pulau Kecil, 2021).

Hutan mangrove memiliki beberapa peranan penting bagi lingkungan, antara lain: mampu meredam gelombang besar termasuk tsunami, mampu mencegah abrasi, mampu menyerap karbondioksida 5 kali lebih besar daripada hutan tropis di dataran tinggi, dan sebagai habitat bagi beberapa jenis satwa liar (Dlh, 2021). Dengan demikian, Indonesia memiliki 
peranan yang signifikan bagi eksistensi dan keberlanjutan hutan mangrove dunia. Berdasarkan data tahun 2018, Propinsi DKI Jakarta memiliki 300 hektar atau sekitar 10,7\% dari total hutan mangrove di Indonesia (Adkhi, 2020). Hutan Mangrove di Provinsi DKI Jakarta tersebar di Taman Wisata Alam Angke Kapuk, Suaka Margasatwa Muara Angke, Hutan Lindung Angke Kapuk dan Hutan Produksi Kamal Muara sekaligus merupakan bagian dari hutan mangrove terakhir yang tersisa di provinsi DKI Jakarta (Solikhah, 2014).

Taman Wisata Alam (TWA) Angke Kapuk merupakan kawasan konservasi alam mangrove seluas 99,82 hektar yang masih terjaga dengan baik dan dimanfaatkan untuk pariwisata dan rekreasi alam dengan mengedepankan pariwisata berkelanjutan (sustainable tourism) (Jakarta, n.d; Febriyanto, 2020). Studi dari Sofian et al., (2020) menunjukkan bahwa dari luasan ekosistem Mangrove Angke Kapuk sebesar 291,17 ha, 94\% diantaranya memiliki tingkat kerapatan jarang, $5,7 \%$ memiliki tingkat kerapatan sedang dan $0.03 \%$ atau 1,54 ha memiliki tingkat kerapatan lebat. Mengacu pada SNI 7717-2020, kondisi mangrove lebat yaitu mangrove dengan tutupan tajuk $>70 \%$, mangrove sedang dengan tutupan tajuk 30-70\%, mangrove jarang dengan tutupan tajuk $<30 \%$. Berdasarkan peranan dari hutan mangrove Angke Kapuk, maka maka diperlukan strategi untuk mengelolanya. Disarikan dari Sasongko et al. (2014), terdapat 8 (delapan) strategi pengelolaan, yaitu: Rehabilitasi ekosistem mangrove, Pemetaan zonasi pengelolaan kawasan, Pengamanan kawasan, Perlindungan ekosistem pantai, Kolaborasi pengelolaan, Publikasi dan promosi, Pendanaan pengelolaan kawasan secara regular dan tahun jamak, dan Pendidikan lingkungan (penyuluhan).

Sebagai upaya dalam menjaga eksistensi dan keberlanjutan hutan mangrove khususnya di Kota Jakarta, salah satu aktor penting yang perlu dilibatkan adalah kalangan remaja. Remaja sebagai pemegang tonggak masa depan perlu memiliki kesadaran akan isu lingkungan.

\section{Permasalahan Mitra}

Berdasarkan hasil identifikasi permasalahan dari topik yang diangkat yaitu eksistensi dan keberlanjutan hutan mangrove serta karakteristik mitra remaja (berusia 12 - 24 tahun) yang tergabung dalam Remaja Masjid At-Taufiq Tanjung Gedong, diketahui bahwa isu lingkungan menjadi topik yang menarik bagi remaja. Namun demikian, diperlukan konsep kegiatan edukasi yang sesuai dengan karakteristik bagi remaja agar isu pentingnya eksistensi dan keberlanjutan hutan mangrove dapat lebih mudah dipahami oleh mitra.

\section{Solusi yang Ditawarkan}

Metode kreatif diperlukan sebagai media pembelajaran bagi kalangan remaja namun belum menjadi bagian dari kurikulum dasar sekolah pada umumnya. Salah satu solusi yang dapat dilakukan adalah dengan mengembangkan design thinking dengan pendekatan critical thinking dan creative thinking (Mawarni et al., 2019). Di sisi lain, diperlukan juga pendekatan yang kreatif agar sejalan dengan kebutuhan remaja di era digital yang tidak terlepas dari media sosial (Sukatin et al., 2021). Oleh karena itu, untuk menumbuhkan antusiasme dari mitra, maka diperlukan pendekatan agar nantinya mitra mengalami proses kreatif berupa pengalaman empiris di lapangan serta mampu membawa dampak positif yang lebih luas untuk mitra.

Penulis menginisiasi kegiatan pengabdian kepada masyarakat (PkM) yaitu edukasi eksistensi dan keberlanjutan ekosistem hutan mangrove bagi remaja (berusia 12 - 24 tahun) yang tergabung dalam Remaja Masjid At-Taufiq Tanjung Gedong. Edukasi tidak hanya bersifat teoritis namun dilaksanakan secara aktif dengan melibatkan partisipasi aktif dari mitra.menggunakan metoda Experiential Learning Discovery Journey melalui pengalaman, observasi, dan refleksi (Tovar \& Misischia, 2018).

Target yang ingin dicapai dari kegiatan PkM adalah agar nantinya mitra memiliki kesadaran akan isu lingkungan, memahami pentingnya eksistensi dan keberlanjutan hutan mangrove 
dan mampu menjadi agen perubahan kesadaran isu lingkungan.

\section{METODE PELAKSANAAN}

Kegiatan PkM mengangkat isu lingkungan terutama upaya untuk menjaga eksistensi dan keberlanjutan hutan mangrove khususnya di Kota Jakarta. Generasi remaja memiliki peranan yang signifikan akan pentingnya eksistensi dan keberlanjutan hutan mangrove. Oleh karena itu, kegiatan pengabdian kepada masyarakat dilaksanakan dengan pendekatan aktivitas yang sesuai dengan karakteristik remaja berupa metoda Experiential Learning Discovery Journey dengan melibatkan partisipasi aktif dari mitra pada setiap tahapan. Experiential learning merupakan teori pedagogis oleh Kolb yang mencerminkan bagaimana pengetahuan siswa dapat ditransformasikan melalui pengalaman, observasi, dan refleksi (Tovar \& Misischia, 2018). Mitra kegiatan yaitu 15 (lima belas) remaja berusia 12-24 tahun yang tergabung dalam Remaja Masjid At-Taufiq Tanjung Gedong, Jakarta Barat.

Metoda Experiential Learning Discovery Journey dalam kegiatan pengabdian kepada masyarakat ini diterapkan selama satu semester melalui 3 tahapan, yaitu:

a. Tahap Pengalaman

Penulis sebagai inisiator kegiatan menyusun materi tentang eksistensi dan pentingnya hutan mangrove (lingkungan dan arsitektur) dalam bentuk infografis dan videografis. Materi yang telah disusun menjadi pengetahuan dasar bagi mitra dalam memahami topik kegiatan. Mitra diberikan arahan untuk melakukan eksplorasi sebagai pengalaman awal.

b. Tahap Observasi

Sesuai dengan karakteristik mitra yaitu generasi remaja, maka tahapan active participatory selanjutnya dengan metoda Experiential Learning Discovery Journey berupa observasi ke Taman Wisata Alam Mangrove, Angke Kapuk, Jakarta Utara. Dengan memiliki pengalaman empiris, remaja akan menjadi lebih aktif dalam memahami informasi yang telah diberikan. Sehingga tujuan dari kegiatan PKM yaitu sebagai media edukasi tentang eksistensi dan pentingnya hutan mangrove (lingkungan dan arsitektur) dapat berjalan efektif.

c. Tahap Reflekasi

Sebagai bagian dari evaluasi, maka penulis menyusun sebuah instrumen melalui kuesioner. Instrumen disusun untuk mengetahui karakteristik mitra, pengalaman awal mitra, efektivitas dan ketercapaian tujuan kegiatan pkm.

Adapun instrumen refleksi yang diberikan kepada mitra melalui link google form sebagai bagian dari tahapan refleksi disampaikan pada tabel 1 berikut.

Table 1. Instrumen refleksi

\begin{tabular}{cl}
\hline 1. & Apakah Anda sudah mengenal/mengetahui Hutan Mangrove sebelumnya? \\
\hline 2. & Jika Ya, kapan Anda pertama kali mengenal/mengetahui tentang Hutan Mangrove? \\
\hline 3. & Apakah Anda pernah mengunjungi Hutan Mangrove sebelumnya? \\
\hline 4. & Bagaimana kesan Anda pertama kali mengunjungi Hutan Mangrove (Taman Wisata Alam Angke Kapuk)? \\
\hline 5. & Bagaimana Anda lebih mudah memahami Karakter dan Manfaat Hutan Mangrove? \\
\hline 6. & Apakah Anda mengetahui manfaat hutan mangrove bagi lingkungan khususnya kawasan pesisir? \\
\hline 7. & Apakah Anda mengetahui manfaat hutan mangrove yang dapat mencegah abrasi dan gelombang laut? \\
\hline 8. & Apakah melalui ilustrasi berikut Anda lebih mudah memahami manfaat Hutan Mangrove? \\
\hline 9. & Apakah Anda setuju jika hutan mangrove dikembangkan menjadi wisata alam? \\
\hline 10. & Apakah video berikut memberikan gambaran dan pengetahuan baru tentang pentingnya hutan mangrove? \\
\hline https://www.youtube.com/watch?v=L6X90C-HvqY \\
\hline Apakah setelah mengunjungi Hutan Mangrove (Taman Wisata Alam Angke Kapuk) Anda sudah lebih memahami \\
\hline 12. & Pengetahuan baru apa yang Anda dapatkan setelah mengunjungi Hutan Mangrove PIK? (bisa lebih dari satu) \\
\hline Sumber: Penulis, 2021
\end{tabular}




\section{HASIL DAN PEMBAHASAN}

Pelaksanaan PkM dilakukan sesuai dengan tahapan Experiential Learning Discovery Journey yang telah dijelaskan sebelumnya. Adapun hasil dan pembahasan dari masing-masing tahapan adalah sebagai berikut:

\section{Tahap Pengalaman}

Diperlukan pengetahuan awal bagi mitra terkait dengan topik yang diambil dari kegiatan PkM. Sesuai dengan karakteristik remaja dan bagian dari creative thinking, maka penulis menyediakan media videografis dan infografis. Panduan videografis berisi informasi terkait karakteristik dan manfaat hutan mangrove serta gambaran beberapa titik hutan mangrove di Indonesia. Panduan awal infografis berisi materi eksistensi dan pentingnya hutan mangrove serta upaya pelestarian hutan mangrove. Materi infografis disusun berdasarkan sudut pandang lingkungan secara umum dan arsitektur yaitu model arsitektur panggung pada bangunan Masjid Al-Hikmah yang berada di kawasan Hutan Mangrove Angke. Berdasarkan hasil wawancara dengan mitra, materi yang diberikan membantu pemahanan mitra terhadap topik yang diangkat. Materi videografis dan infografis sebagai materi pengalaman awal dapat diilihat pada gambar 1 dan 2 .

\section{Tahap Observasi}

Sesuai dengan karakteristik mitra yaitu generasi remaja, maka tahapan Experiential Learning Discovery Journey selanjutnya dengan active

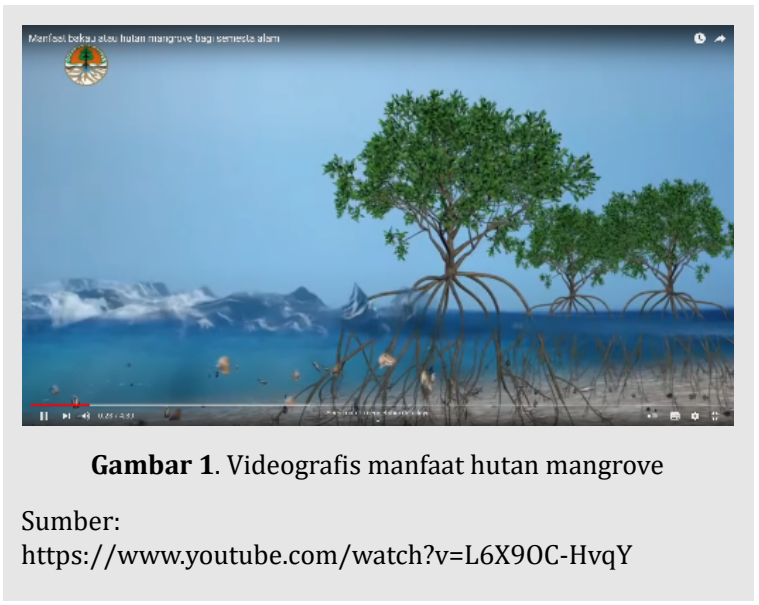

participatory berupa observasi ke Taman Wisata Alam Mangrove, Angke Kapuk, Jakarta Utara. Dengan memiliki pengalaman empiris, remaja akan menjadi lebih aktif dalam memahami informasi yang telah diberikan. Sehingga tujuan dari kegiatan PkM yaitu sebagai media edukasi tentang eksistensi dan pentingnya hutan mangrove (lingkungan dan arsitektur) dapat berjalan efektif.

Mitra mendapatkan pengalaman empiris tentang karakteristik alam dari hutan mangrove, proses pembibitan dan pemeliharaan tanaman bakau, serta upaya pemanfaatan dari hutan mangrove sebagai taman wisata alam sekaligus sebagai media edukasi bagi masyarakat.

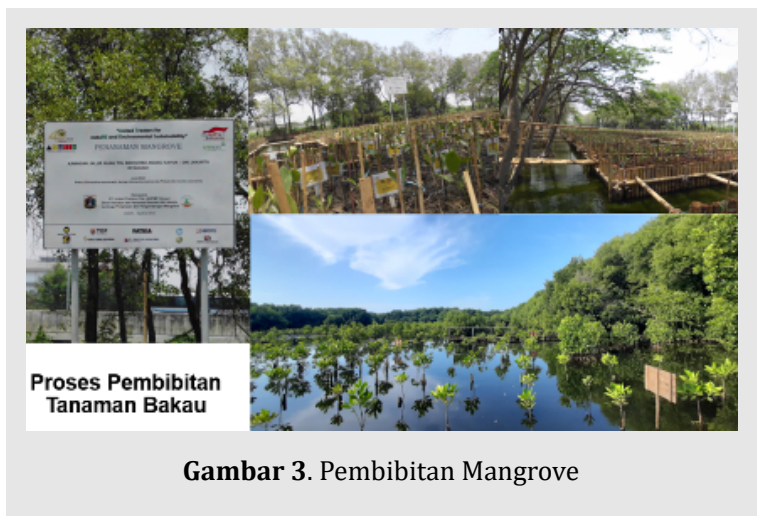

Selama kegiatan observasi, mitra juga melakukan kegiatan peliputan (gambar 4). Hal ini menjadi pengalaman empiris dan berkesempatan membagikan konten edukasi kepada kalangan yang lebih luas. Sehingga

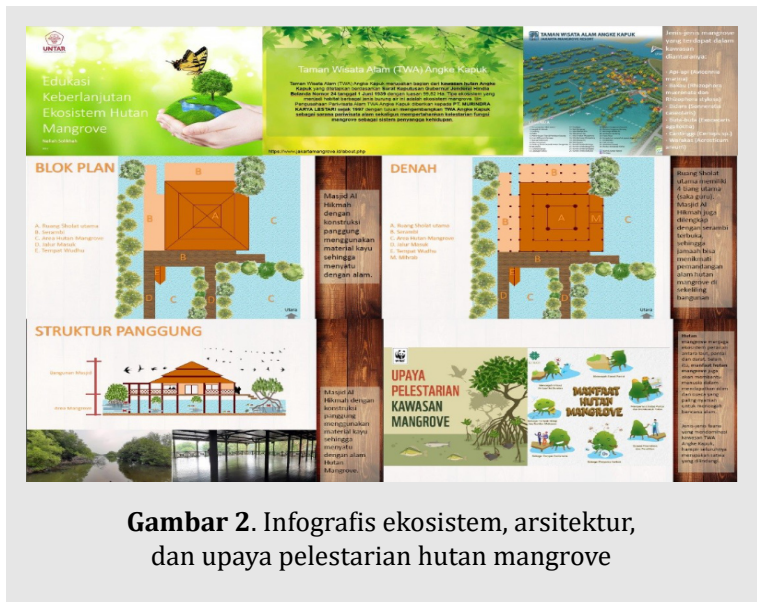


manfaat dari kegiatan PkM juga dapat dterima oleh kalangan yang lebih luas terutama bagi generasi milenial yang tidak terlepas dari media sosial.

Pada tahap observasi, mitra juga mendapatkan pengalaman langsung dari edukasi lingkungan hutan mangrove dan edukasi arsitektur berkelanjutan yaitu model arsitektur panggung pada bangunan Masjid Al-Hikmah yang berada pada lokasi kegiatan PkM di Taman Wisata Alam Mangrove, Angke Kapuk, Jakarta Utara (gambar 5).

\section{Tahap Refleksi}

Setelah dilaksanakan tahap pengenalan dan tahap observasi, maka dilakukan tahap refleksi berupa evaluasi efektivitas dari kegiatan edukasi aktif kepada 15 peserta berdasarkan instrumen yang telah disusun. Instrumen disusun untuk mengetahui karakteristik mitra, pengalaman awal mitra, efektivitas dan ketercapaian tujuan kegiatan PkM.

Sebagian besar peserta $(93,3 \%)$ sudah mengenal dan mengetahui manfaat dari hutan mangrove yang didapatkan dari materi sekolah SMP dan SMA), media sosial, dan kunjungan. Pengalaman awal tersebut menjadi bekal bagi peserta dalam mengikuti kegiatan PkM (gambar 6).

Meskipun hampir seluruh peserta sudah memiliki pengenalan awal tentang hutan mangrove, namun sebagian besar responden $(73,3 \%)$ belum memiliki pengalaman berkunjung secara langsung di lapangan (gambar 7). Hal tersebut menunjukkan bahwa pengalaman awal yang dimiliki oleh mitra baru sebatas pengalaman teoretis serta perlu adanya kombinasi edukasi yang kreatif.

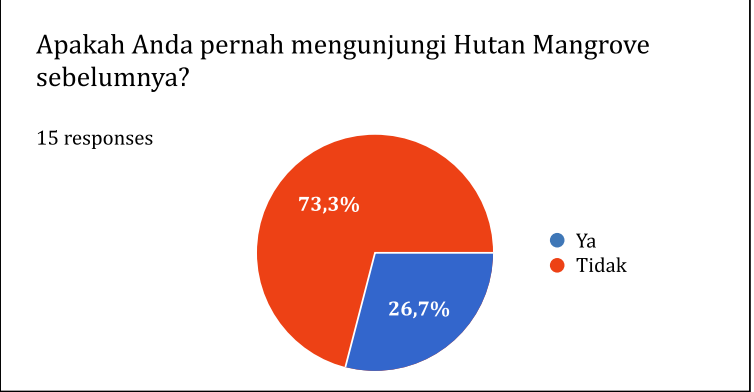

Gambar 7. Pengalaman kunjungan mitra

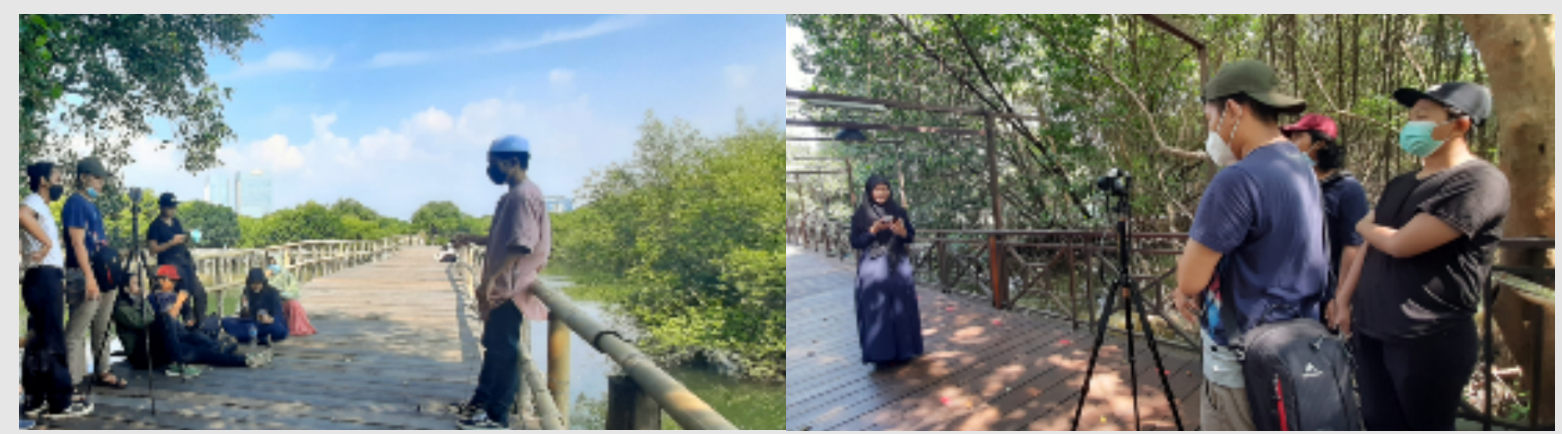

Gambar 4. Mitra juga melakukan liputan selama kegiatan

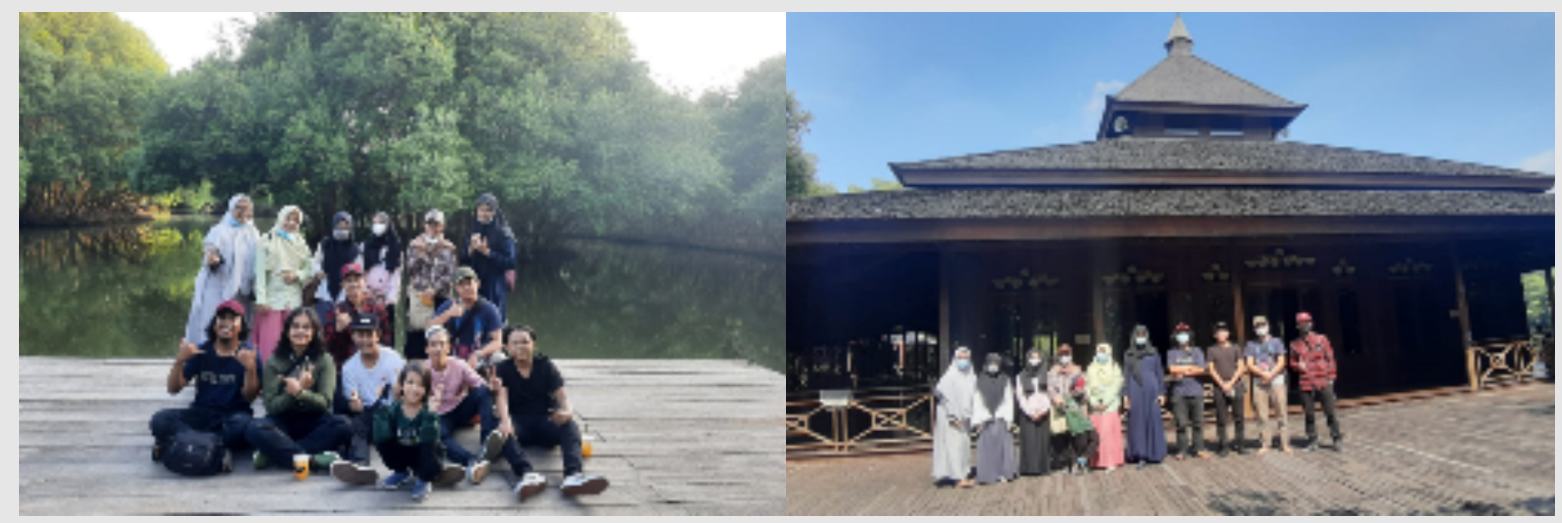

Gambar 5. Dokumentasi observasi pada tanggal 13 Juni 2021 
Apakah Anda sudah mengenal/mengetahui Hutan Mangrove sebelumnya?

15 responses

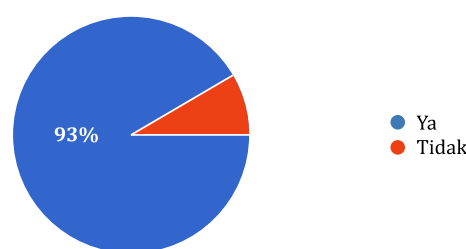

Apakah Anda mengetahui manfaat hutan mangrove bagi lingkungan khususnya kawasan pesisir?
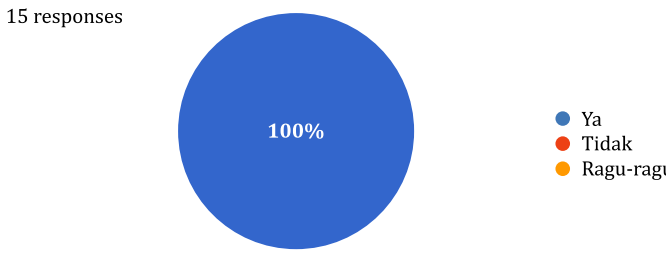

Apakah Anda mengetahui aktifitas pada gambar tersebut 15 responses

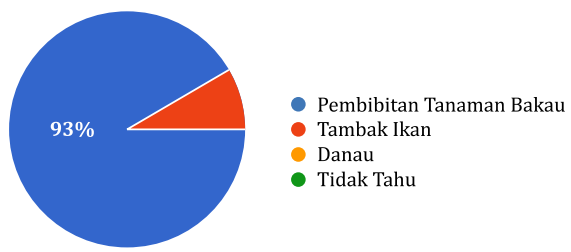

Jika Ya, kapan Anda pertama kali mengenal/mengetahui tentang Hutan Mangrove?

15 responses

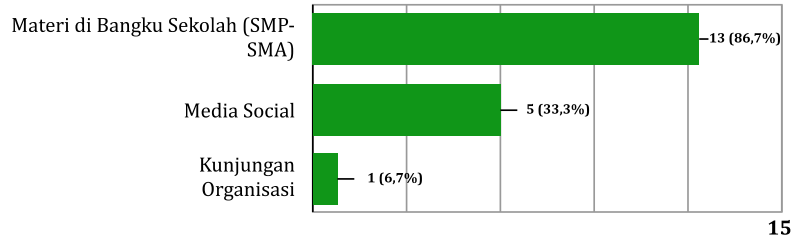

Apakah Anda mengetahui manfaat hutan mangrove yang dapat mencegah abrasi dan gelombang laut?
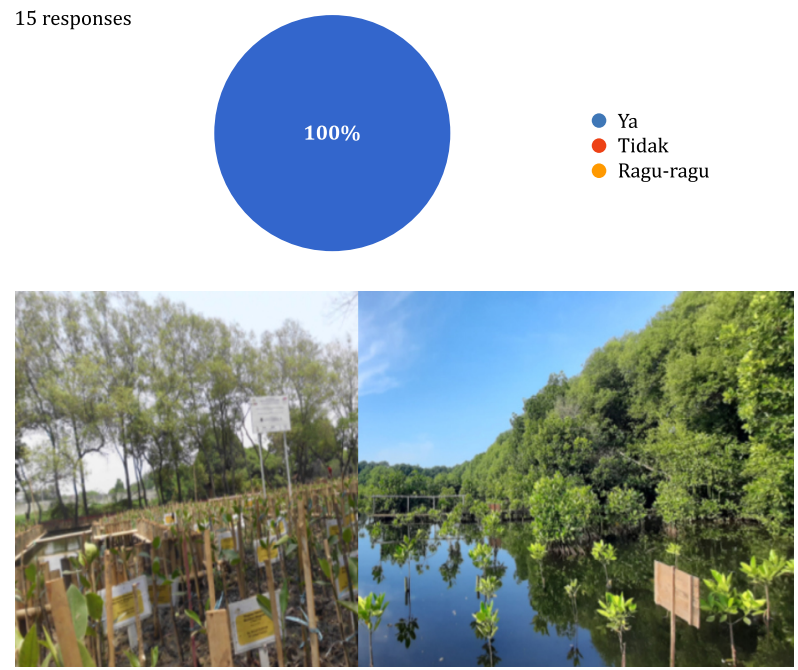

Gambar 6. Pengetahuan awal mitra

Tahapan observasi dengan berupa kunjungan ke Taman Wisata Alam Mangrove, Angke Kapuk, Jakarta Utara memberikan kesan yang positif bagi mitra karena mitra mendapatkan pengalaman aktif untuk melihat secara langsung ekosistem dan arsitektur hutan mangrove (gambar 8). Melalui pengalaman empiris dengan observasi langsung, mitra lebih mudah memahami pembuktian informasi dari videografis dan infografis terkait eksistensi dan keberlanjutan hutan magrove yang telah diberikan pada tahap pengenalan. Hal tersebut menunjukkan bahwa langkah awal yang dilakukan oleh penulis sudah sesuai dengan karakteristik pembelajaran bagi remaja dan memudahkan mitra dalam memahami informasi awal.

Sebagai bagian dari Experiential Learning Discovery Journey, maka media informasi juga memiliki peranan penting dalam menyampaikan informasi kepada mitra agar lebih efektif dan sesuai dengan karakteristik remaja. Berdasarkan insrumen, dalam tahap pengenalan, mitra lebih mudah memahami informasi melalui videografis dan infografis sebagai pengenalan awal terkait topik kegiatan PkM yang dibuktikan dengan pemahaman pada saat tahap observasi (gambar 9).

Bagaimana kesan Anda pertama kali mengunjungi Hutan Mangrove (Taman Wisata Alam Angke Kapuk)?

15 responses

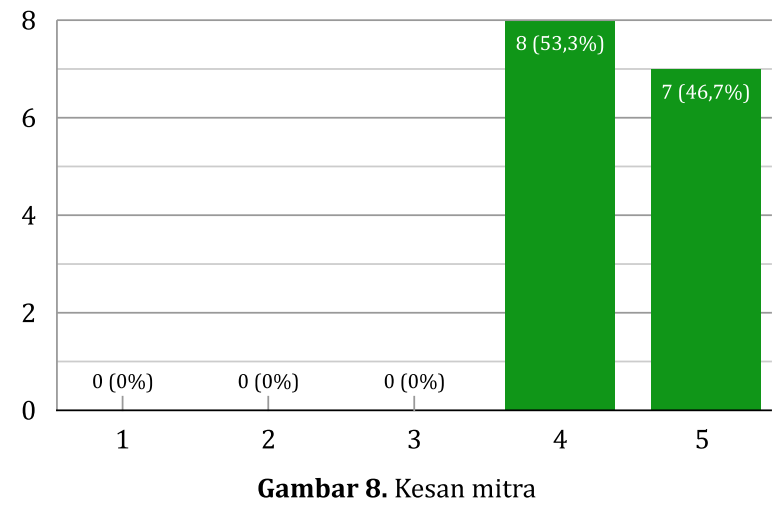


Bagaimana Anda lebih mudah memahami Karakter dan Manfaat Hutan Mangrove?

15 responses

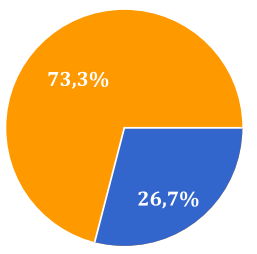

Datang dan melihat langsung.

Membaca Buku/Video/Ilustrasi

Keduanya.

Apakah melalui ilustrasi berikut Anda lebih mudah memahami manfaat Hutan Mangrove?

15 responses

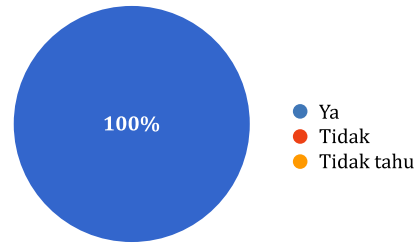

Apakah video berikut memberikan gambaran dan pengetahuan baru tentang pentingnya hutan mangrove? https://www.youtube.com/watch?v=L6X90C-HvqY

15 responses
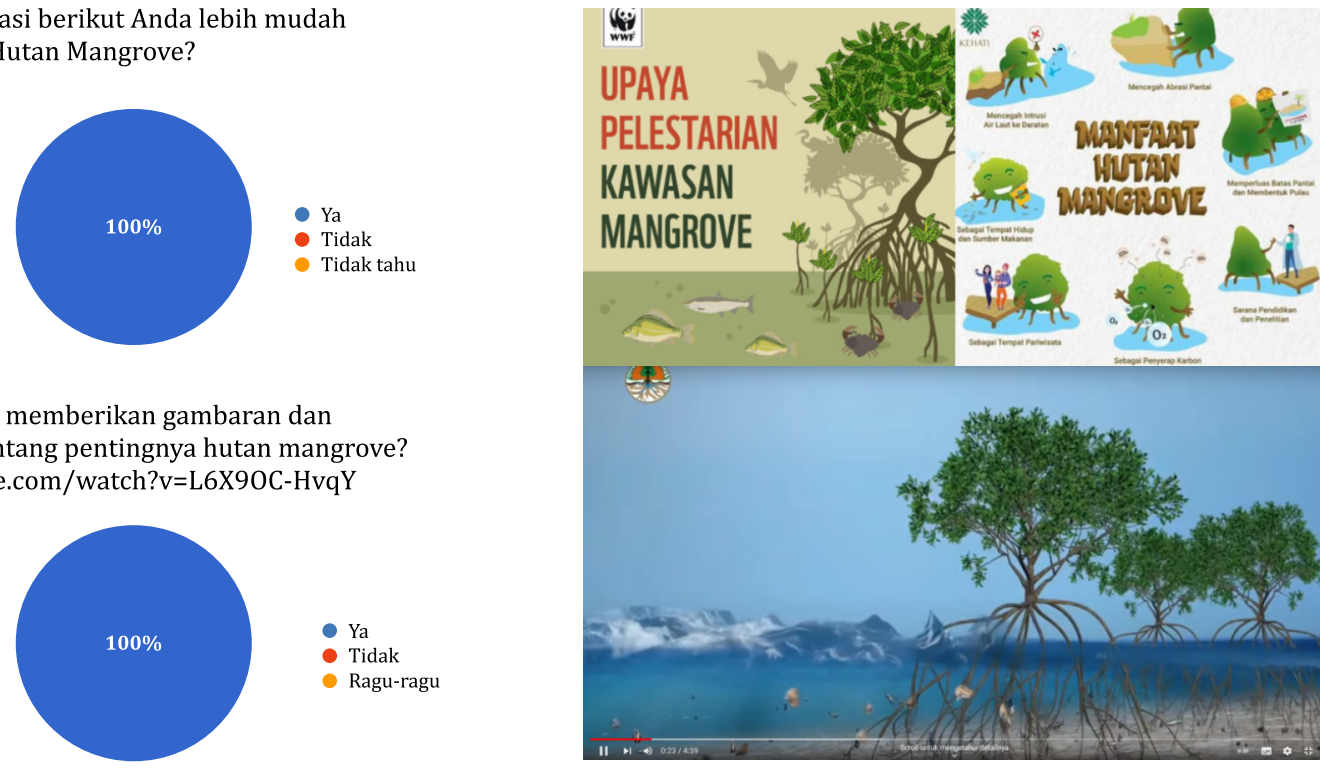

Gambar 9. Pemahaman Mitra

Apakah setelah mengunjungi Hutan Mangrove

(Taman Wisata Alam Angke Kapuk) Anda sudah lebih memahami karakteristik dan peranan Hutan Mangrove terhadap ekosistem?

15 responses

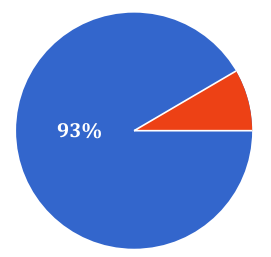

Pengetahuan baru apa yang Anda dapatkan setelah mengunjungi Hutan Mangrove PIK? (bisa lebih dari satu)

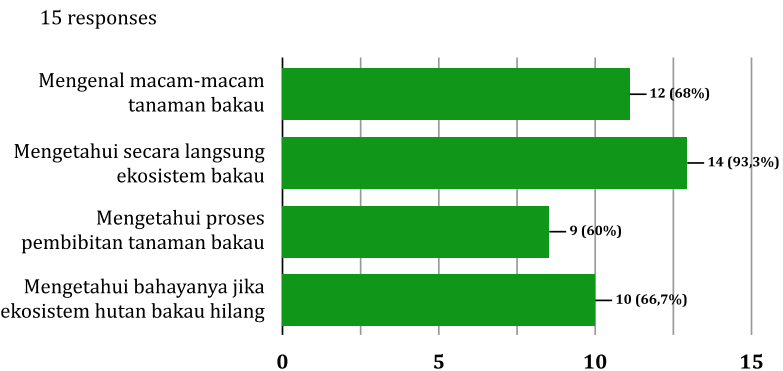

Gambar 10. Indikasi keberhasilan program

Terkait pemanfaatan hutan mangrove, 93,3\% peserta menyatakan setuju jika hutan mangrove dikembangkan menjadi wisata alam sekaligus sebagai media edukasi bagi masyarakat karena mitra merasakan manfaat langsung dari Taman Wisata Alam (TWA) Angke Kapuk sebagai kawasan konservasi alam mangrove yang masih terjaga dengan baik dan dimanfaatkan untuk pariwisata dan rekreasi alam dengan mengedepankan pariwisata berkelanjutan (sustainable tourism) (gambar 10).

Berdasarkan gambar 10, program PkM berhasil meningkatkan kesadaran dan pemahaman peserta berupa pengetahuan baru tentang eksistensi dan keberlanjutan hutan mangrove setelah mengikuti kegiatan PkM. Pengetahuan baru tersebut meliputi:

a. Mengenal macam-macam tanaman bakau.

b. Mengetahui secara langsung ekosistem bakau. 
c. Mengetahui proses pembibitan tanaman bakau.

d. Mengetahui dampak negatif lingkungan jika ekosistem hutan bakau hilang.

\section{KESIMPULAN DAN SARAN}

\section{Kesimpulan}

Isu lingkungan menjadi topik yang signifikan untuk diangkat terutama bagi mitra remaja sebagai pemegang tonggak masa depan yang perlu memiliki kesadaran akan isu lingkungan. Berdasarkan hasil kegiatan, diketahui bahwa seluruh responden telah memiliki pengetahuan dasar tentang eksistensi dan peranan hutan mangrove bagi lingkungan, namun masih terbatas pada teori yang didapatkan pada bangku sekolah. Melalui kegiatan PkM edukasi dengan pendekatan Experiential Learning Discovery Journey yang dilaksanakan dalam 3 (tiga) tahap, yaitu pengenalan, observasi, refleksi menjadi kegiatan edukasi yang efektif bagi mitra. Hal ini karena seluruh mitra terlibat secara aktif dalam setiap tahapan (active participatory), sehingga mampu meningkatkan pemahaman terhadap topik PkM yaitu eksistensi dan keberlanjutan ekosistem hutan mangrove di Jakarta.

\section{Saran}

Berdasarkan evaluasi yang telah dilakukan dapat diajukan beberapa saran sebagai berikut:

a. Perlu adanya integrasi pada proses pembelajaran mata pelajaran di sekolah dengan pendekatan Experiential Learning Discovery Journey, terutama untuk menumbuhkan kreativitas belajar-mengajar.

a. Perlu adanya kegiatan lanjutan dengan mitra sasaran yang lebih luas.

\section{R E F E R E N C E}

Adkhi, I. I. (2020). Reboisasi Hutan Mangrove di Teluk Jakarta. https://www.kompasiana.com/iiditsna/ 5ea2a895097f360a846ac822/reboisasi-hutan-mangrove-di-teluk-jakarta?page=all\#sectionall

Bunting, P., Rosenqvist, A., Lucas, R. M., Rebelo, L. M., Hilarides, L., Thomas, N., Hardy, A., Itoh, T., Shimada, M., \& Finlayson, C. M. (2018). The global mangrove watch - A new 2010 global baseline of mangrove extent. Remote Sensing, 10(10), 1669. https://doi.org/10.3390/rs10101669

Direktorat Pendayagunaan Pesisir dan Pulau-Pulau Kecil, K. K. dan P. R. (2021). Kondisi Mangrove di Indonesia. Direktorat Pendayagunaan Pesisir Dan Pulau-Pulau Kecil, Kementerian Kelautan Dan Perikanan RI. https://kkp.go.id/djprl/p4k/page/4284-kondisi-mangrove-di-indonesia

Dlh, A. (2021). Pentingnya Hutan Mangrove bagi Lingkungan Hidup. Pemerintah Kabupaten Buleleng Dinas Lingkungan Hidup. https://dlh.bulelengkab.go.id/informasi/detail/artikel/60-pentingnya-hutan-mangrove-bagilingkungan-hidup

Febriyanto, 0. (2020). Strategi Pengembangan Kawasan Ekowisata Mangrove Pantai Indah Kapuk Sebagai Daya Tarik Di DKI Jakarta. Geomedia, 18(1), 1-11. https://journal.uny.ac.id/index.php/ geomedia/index\%0AStrategi

Jakarta, T. M. (n.d.). Taman Wisata Alam (TWA) Angke Kapuk. Retrieved June 6, 2021, from https://www.jakartamangrove.id/

Mawarni, I. A. S. D., Akbar, R., \& Mukhlis, A. M. A. (2019). Design Thinking Sebagai Metode Edukasi Kreatif Anak Usia Remaja. Prosiding Konferensi Nasional Pengabdian Kepada Masyarakat Dan Corporate Social Responsibility (PKM-CSR), 2, 984-991. https://doi.org/10.37695/pkmcsr.v2i0.611

Putra, I. S. (2019). Dampak Pulau Reklamasi terhadap Sedimentasi dan Potensi Perkembangan Mangrove Di Pesisir Teluk Jakarta (Muara Angke). Jurnal Sumber Daya Air, 15(2), 81-94. https://doi.org/10.32679/jsda.v15i2.587 
Sasongko, D. A., Kusmana, C., \& Ramadan, H. (2014). Strategi Pengelolaan Hutan Lindung Angke Kapuk [Management Strategy of Angke Kapuk Protected Forest]. Jurnal Pengelolaan Sumberdaya Alam Dan Lingkungan, 4(1), 35-42.

Sofian, A., Kusmana, C., Fauzi, A., Rusdiana, O., \& Kapuk, L. A. (2020). Evaluasi Kondisi Ekosistem Mangrove Angke Kapuk Teluk Jakarta dan Konsekuensinya Terhadap Jasa Ekosistem. Jurnal Kelautan Nasional, 15(1), 1-12. http://dx.doi.org/10.15578/jkn.v15i1.7722

Solikhah, N. (2014). Kajian Pola Spasial Permukiman Nelayan Muara Angke, Jakarta Utara. Prosiding Seminar Nasional ARSITEKTUR MERAH-PUTIH: Ruang Dan Tempat Dalam Latar Indonesia, 149-157.

SNI 7717-2020: Spesifikasi informasi geospasial - Mangrove skala 1:25.000 dan 1:50.000

Sukatin, Ma'ruf, A., Putri, D. M., Karomah, D. G., \& Hania, I. (2021). Urgensi Pendidikan Karakter Bagi Remaja Di Era Digital. SOSAINS: Jurnal Sosial Dan Sains, 1(9), 1101-1111. https://doi.org/https://doi.org/10.36418/sosains.v1i9.205

Tovar, L. A., \& Misischia, C. (2018). Experiential learning: transformation and discovery through travel study programs. Research in Higher Education Journal, 35, 1-15.

https://www.youtube.com/watch?v=L6X90C-HvqY 